EDITOR'S

\title{
Diagnosis of breast lesions: fine-needle aspiration cytology or core needle biopsy? A review
}

\author{
S M Willems, ${ }^{1} \mathrm{C} \mathrm{H} \mathrm{M}$ van Deurzen, ${ }^{2} \mathrm{P} \mathrm{J}$ van Diest ${ }^{1}$
}

'Department of Pathology, University Medical Center, Utrecht, The Netherlands ${ }^{2}$ Department of Pathology, Erasmus Medical Center, Rotterdam, The Netherlands

\section{Correspondence to}

Stefan M Willems, Department of Pathology, University Medical Center Utrecht, Heidelberglaan 100, 3584 CX Utrecht, The Netherlands;

s.m.willems-4@umcutrecht.nl

Accepted 27 September 2011 Published Online First 29 October 2011

\begin{abstract}
Diagnosis of breast lesions is routinely performed by the triple assessment of a specialised surgeon, radiologist and pathologist. In this setting, fine-needle aspiration cytology (FNAC) and core needle biopsy (CNB) are the current methods of choice for pathological diagnosis, both with their specific advantages and limitations. Evidence-based literature discussing which of both modalities is preferable in breast lesion diagnosis is sparse and there is no consensus among different specialised breast cancer centres. This study reviews FNAC and CNB for diagnosing breast lesions, comparing methodological issues, diagnostic performance indices, possibilities for additional prognostic and predictive tests and cost effectiveness. Overall, CNB achieved better sensitivity and specificity especially in those lesions that were not definitively benign or malignant, non-palpable and/or calcified lesions. Although FNAC is easier to perform, interpretation requires vast experience and even then, it is more often inconclusive requiring additional CNB. The authors conclude that overall CNB is to be preferred as a diagnostic method.
\end{abstract}

Diagnosis of breast lesions is routinely performed by the combined assessment of (at least) a specialised surgeon, radiologist and pathologist, usually through a multidisciplinary meeting. Fine-needle aspiration cytology (FNAC) and core needle biopsy (CNB) are currently widely used methods for pathological diagnosis, both with their specific advantages and limitations. Evidence-based literature discussing which of the modalities is to be preferred for the diagnosis of breast lesions is sparse and there seems no real consensus on their place, even among specialised breast cancer centres, although some centres tend to favour $\mathrm{CNB}$ in specific cases. ${ }^{12}$ In this article, we will review FNAC and $\mathrm{CNB}$ for breast lesion diagnosis, comparing methodological issues, diagnostic performance indices, possibilities for additional prognostic and predictive tests and cost effectiveness.

\section{DIAGNOSTIC PERFORMANCE INDICES}

As for any diagnostic procedure a high negative predictive value is important to minimise undertreatment; a high positive predictive value reduces the risk of overtreatment. Therefore, high sensitivity and specificity are crucial as they are the key determinants of both negative and positive predictive values. The overall sensitivity and specificity of FNAC and CNB in the classification of breast lesions depend on variables intrinsic to the technique as well as related to radiological/clinical and histological features. Comparison of results of the different studies on the performance of FNAC and $\mathrm{CNB}$ that have not standardised these parameters may not be fully possible. Studies comparing the accuracy of FNAC and CNB within the same patient population are relatively scarce. Nevertheless, overall but not invariably, CNB has both higher sensitivity and specificity than FNAC in diagnosing benign and malignant lesions (figure 1). ${ }^{3-31}$ One of the largest studies so far reported sensitivity, specificity, positive and negative predictive values of $97.1 \%, 99.1 \%, 99.3 \%$ and $96.2 \%$ for FNAC. ${ }^{21}$ However, it should be noted that the study included only definitive benign and malignant lesions, ignoring the atypical and suspicious categories, which account for up to $20 \%$ of breast lesions in daily pathology. ${ }^{21}$ Indeed, Westenend et $a l^{8}$ reported that the positive predictive value of FNAC for malignancy was comparable with CNB (ie, 99-100\%), but that this rate decreased to $78 \%$ for suspicious lesions (100\% for CNB) and was only $18 \%$ in case of atypia ( $80 \%$ for CNB). So, in general $\mathrm{CNB}$ achieved higher performance indices when compared with FNAC across different studies.

\section{PROCEDURAL (DIS)ADVANTAGES}

FNAC and CNB are methologically different and have their own advantages and disadvantages. In general, FNAC is more suitable for patients on anticoagulants and for lesions close to the skin, chest wall, vessels and implant or for very small lesions and those that are deep seated and difficult to reach. For accessible, palpable lesions FNAC can be performed relatively straightforwardly and takes approximately $5 \mathrm{~min}$ in experienced hands. Therefore and for these cases, FNAC is easier to plan than CNB in an outpatient clinic. This advantage is often used as a strong argument in favour of FNAC over CNB, although it can be (partly) circumvented by optimising the logistical workflow. As a general feature of cytology, good quality FNAC depends on the competence of the aspirator, and its interpretation is primarily determined by the skills and experience of the (cyto)pathologist. ${ }^{2632-34}$ The main complication of both FNAC and $\mathrm{CNB}$ is pain, the intensity of which seems to correlate with the diameter of the needle, but might be influenced significantly by other factors such as stress. ${ }^{35-38}$ For both FNAC and CNB, infection and haematoma formation requiring medical intervention are rare $(0-2 \%)$, whereas the risk of pneumothorax is very rare $(<0.05 \%) .{ }^{13} 39-43$

\section{DEPENDENCE OF DIAGNOSTIC PERFORMANCE ON} CLINICAL/RADIOLOGICAL FEATURES

The success rate of FNAC for obtaining a definite (malignant) diagnosis depends both on the 
A

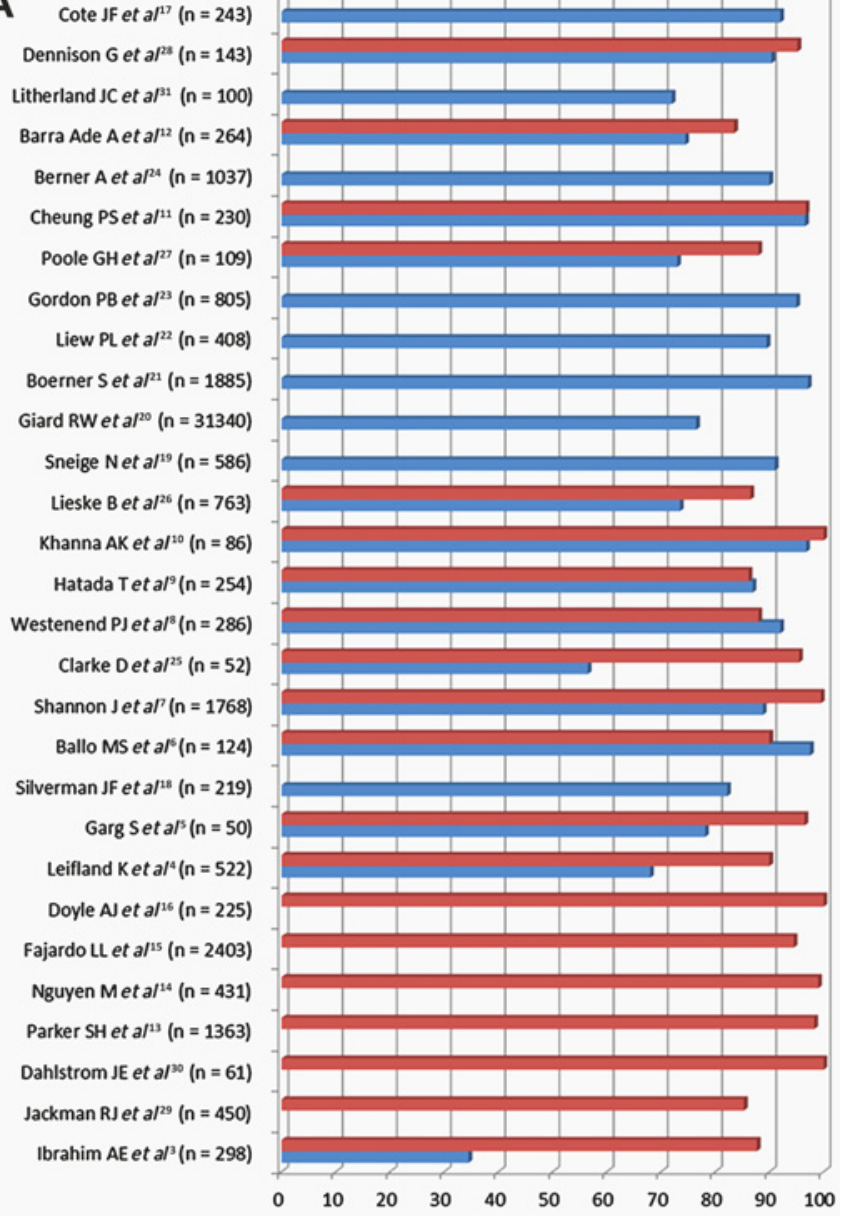

B Cote Jf et $\mathrm{a}^{17}(\mathrm{n}=243)$ Barra Ade Aet a ${ }^{12}(n=264)$ Berner A et $a^{24}(n=1037)$ Cheung PS et $a{ }^{11}(n=230)$ Gordon PB et a ${ }^{23}(n=805)$ Liew PL et $a^{22}(n=408)$ Boerner Set a I $^{21}(n=1885)$ Giard RW et a ${ }^{20}(n=31340)$ Sneige $N$ et a ${ }^{19}(n=586)$ Khanna AK et $a^{10}(n=86)$ Hatada Tet $a a^{\circ}(n=254)$ Westenend PJ et als $(n=286)$ Shannon Jet $a^{\prime}(n=1768)$ Ballo MS et $a^{/ 6}(n=124)$ Silverman Jf et al's $(n=219)$ Garg Set al $/ 5 n=50)$ Leifland Ket $a^{4}(n=522)$ Doyle A et a $a^{16}(n=225)$ Fajardo LL et al $15(n=2403)$ Nguyen Met a ${ }^{14}(n=431)$ Parker SH et a/13 $(n=1363)$ Ibrahim AE et al' $(n=298)$

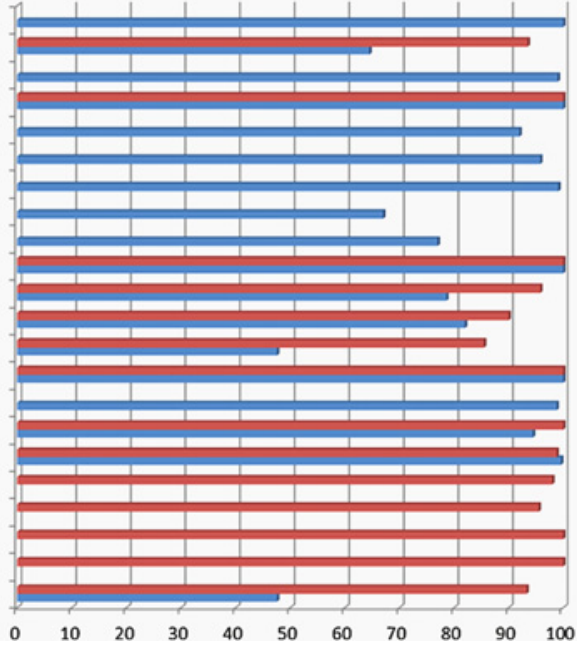

Figure 1 Sensitivity $(A)$ and specificity $(B)$ of fine-needle aspiration cytology (FNAC) and core needle biopsy (CNB) in diagnosing malignant breast tumours. top bar: CNB; lower bar: FNAC. The sensitivity of FNAC in different studies (from 35\% to 95\%) showed more variability and was generally lower compared with CNB (ranging from $85 \%$ to $100 \%$ ). The specificity of FNAC (ranging from $48 \%$ to $100 \%$ ) was also generally lower than CNB (ranging from $86 \%$ to $100 \%$ ).

palpability and size of the lesion. FNAC has average success rates of $75-90 \%$ for palpable and $34-58 \%$ for non-palpable breast lesions, whereas success rates for CNB were $97 \%$ and $94 \%$, respectively. ${ }^{3} 4445$ FNAC has a success rate of only $50 \%$ for lesions less than $10 \mathrm{~mm}$, while CNB is successful in over $90 \%$ of such lesions. Therefore, the success rate of FNAC seems to be especially low for non-palpable lesions and for those smaller than $10 \mathrm{~mm} .{ }^{46}$ Accuracy rates for FNAC are also decreased for large tumours $(>4 \mathrm{~cm}$ ) and calcified lesions are also significantly associated with a higher rate of insufficient sampling than masses. ${ }^{45} 47-49$

\section{DEPENDENCE OF DIAGNOSTIC PERFORMANCE ON HISTOLOGICAL FEATURES}

Apart from radiological and clinical features, diagnostic accuracy predominantly depends on the morphological diagnosis in various studies.

\section{(Pre)malignant lesions}

An important issue in daily practice is discrimination between in-situ (eg, ductal carcinoma in situ; DCIS) and invasive lesions. Although, per definition, cytology is unable to make the claim of invasion in the strictest sense of the word (ie, invasion through the basal membrane), several studies reported criteria to predict invasion on the basis of cytological features. These include infiltration in fragments of fat, infiltration in fibrous tissue fragments, proliferation of fibroblasts and elastoid stromal fragments. The first two features are considered to be most important, although pre-existent ducts can also be surrounded by fat in physiological conditions, and over-interpretation of these criteria has led to false positive cases. ${ }^{50}$ The overall sensitivity and specificity of the aforementioned criteria are, however, low, with 38\% of invasive carcinomas showing none of these criteria, while $29 \%$ of DCIS showed at least one. ${ }^{50}$ In particular, diagnosis of tubular carcinoma and invasive lobular carcinoma is more difficult on FNAC than on CNB. So, even with these criteria in hand, it is very difficult to affirm invasive carcinoma by FNAC whereas it is much easier to do using CNB. It is worth mentioning that approximately $20 \%$ of patients with a CNB diagnosis of DCIS have invasive carcinoma in the excision specimen. This proportion varies according to the gauge of needle. ${ }^{51} \mathrm{CNB}$ is also a more robust method to distinguish between invasive lobular and invasive ductal carcinoma, based on histological and immunohistochemical features. This preoperative distinction may be clinically relevant for: (1) planning the extent of the surgical operation especially if they are considering breast-conserving surgery; (2) considerations regarding neoadjuvant chemotherapy; and (3) the increased risk of contralateral disease in the case of invasive lobular carcinoma warranting contralateral radiological examination (MRI). ${ }^{52-55}$

\section{High-risk lesions}

CNB is an accurate method to diagnose so-called high-risk lesions such as atypical ductal hyperplasia, lobular carcinoma in situ, atypical papillomatosis and columnar cell lesions. Recognition of these lesions is important as they can mimic, and are often associated with, further advanced lesions, and indicate an increased risk of invasive cancer during follow-up. ${ }^{56} 57$ The increased use of vacuum-assisted biopsies and the intact biopsy procedure, by which a semi-invasive mini-resection can be performed, has raised the question of whether an open surgical excision is always warranted for these lesions. ${ }^{58}$ The intact biopsy procedure, which differs from core devices in that it removes one spheroid specimen rather than smaller cylindrical cores, can be performed safely and accurately and tends to have fewer underestimations of DCIS compared with CNB. ${ }^{58} 59$ 


\section{Papillary lesions}

Papillary lesions comprise a spectrum from benign duct papilloma to papillary carcinoma. In general, the diagnostic accuracy of FNAC for papillary lesions is variable but low. ${ }^{60-63}$ Cytological features to distinguish between benign and malignant papillary lesions include papillary fronts, overall cellularity, epithelial cell balls, single cells (with or without atypia) and plasmacytoid cells. These criteria are helpful but not unanimous, and the overall accuracy of FNAC to predict benign from malignant papillary lesions is poor, especially for diagnosing malignant lesions. ${ }^{61}$ The accuracy of $\mathrm{CNB}$ in the histological diagnosis and classification of papillary lesions in the breast is also moderate. The most difficult differential diagnosis is between papillary carcinoma in situ and papilloma, especially if the latter is complicated by florid epithelial hyperplasia, atypical hyperplasia or carcinoma in situ. Immunohistochemistry has recently been shown to be helpful as benign papillary lesions can express high molecular weight cytokeratins (CK5/6, CK14, 34betaE12), are surrounded by myoepithelial cells and show heterogeneous staining for oestrogen receptor (ER). ${ }^{60} \quad 64 \quad 65$ However, false positive and false negative interpretation cannot be excluded and surgical (diagnostic) excision for papillary lesions is recommended, although removal with a vacuumassisted biopsy device is a reasonable option if there is no atypia on the core biopsy.

\section{Fibroepithelial lesions}

Fibroepithelial lesions of the breast encompass commonly occurring fibroadenomas and rare phyllodes tumours. ${ }^{66}$ The latter can be potentially malignant and require complete excision with an adequate margin to prevent recurrences. ${ }^{67}$ The differential diagnosis between both entities by FNAC is challenging and is hampered by the shortage of universally accepted cytological criteria. ${ }^{68}$ Immunohistochemistry on $\mathrm{CNB}$ has recently been shown to be helpful, although its use in routine practice is still limited and setting reliable cut-off values is hampered, for example, for Ki-67, which shows a large overlap between phyllodes tumour and fibroadenoma. ${ }^{69}$ Accuracy rates by FNAC and $\mathrm{CNB}$ are moderate to high, respectively. ${ }^{70} 71$ Regarding the grade of phyllodes tumours, both FNAC and CNB perform suboptimally. This is mainly due to the heterogeneity of phyllodes tumours with regard to both stromal cellularity and (lack of) epithelial atypia. On one hand, sampling areas with only low cellularity of a relatively large amount of sheets of epithelial cells with only mild atypia increases the risk of underestimation of the severity of the lesion. On the other hand, an epithelial proliferation with mild atypia and limited discohesion in a FNAC of a histologically unsuspicious fibroadenoma may result in overestimation of the severity of the lesion.

\section{Normal breast tissue versus benign lesions}

As a general rule, a definite benign diagnosis and distinction between benign and normal breast tissue can be made on $\mathrm{CNB}$. By comparison, benign and normal lesions are often difficult to distinguish with FNAC.

\section{Calcifications}

The assessment of calcification in a core biopsy is much more sophisticated than in FNAC, as the calcification can be seen in the tissue section within the lesion. Moreover, CNB enables a comparison of the pattern of calcification in the core biopsy with that seen on the x-ray. This is why in the UK breast screening programme it is recommended that core biopsy, rather than FNAC, is used for the assessment of calcification.
ASSESSMENT OF PROGNOSTIC AND PREDICTIVE BIOMARKERS

The increased use of neoadjuvant therapy has prompted the need for reliable preoperative assessment of histological and immunohistochemical prognostic and predictive features. For example, grading of malignant breast tumours is an independent prognostic factor. Cytological grading on FNAC correlates quite well with histological grading on $\mathrm{CNB}$ and morphometry on FNAC has been shown to be of some help. ${ }^{72-74}$ However, as FNAC cannot reliably discriminate between DCIS and invasive carcinoma, the value of the cytological grade of a malignant FNAC remains unclear. Moreover, correlation in grade between $\mathrm{CNB}$ and excision specimens on H\&E slides is limited, sometimes with an underestimation on biopsy, but better concordance can be obtained with additional immunohistochemical markers although there is no overall agreement on cut-off values. ${ }^{75-83}$ Therefore, despite some centres assessing histological grade on immunohistochemical/H\&E staining, this is not recommended, neither on FNAC nor on CNB.

In the (neo)adjuvant setting, assessment of $\mathrm{ER}$, progesterone receptor (PR) and HER2 status is crucial and receptor status is routinely determined on (preoperative) biopsies in many pathology laboratories. It is generally accepted that ER, PR and HER2 can be reliably assessed on CNB but not on FNAC. ${ }^{84} 85$ The same holds true for proliferation assessment, which is part of grading and is prognostically very important. ${ }^{86}$ During the past decade with the introduction of small molecule inhibitors, molecular profiling of (breast) tumour samples is increasingly important. In this respect, it is noteworthy that CNB contains RNA/DNA in a sufficient amount and of sufficient quality for molecular testing (eg, arrays), whereas this can be problematical in the case of FNAC in which the yield is often limited.

\section{COSTS AND SPEED}

There is no doubt that the technical costs for a single FNAC is lower than for $\mathrm{CNB}$. However, the overall costs do not only depend on the procedural costs of one sampling procedure, but on the total costs to obtain a reliable definitive diagnosis. In this respect, CNB might paradoxically even be superior to FNAC, at least in selected cases. FNAC may be more cost effective for palpable lesions (with inadequacy rates of $<10 \%$ ), the additional cost for imaging guidance required for non-palpable lesions makes this procedure less cost effective in general. ${ }^{18} 4587$ Even with imaging guidance, the rate of insufficient samples yielded by FNAC varied between $29 \%$ and 39\%. An interesting study showed that indefinite diagnosis using FNAC required additional CNB in $32 \%(93 / 289)$ of cases and additional surgical excision biopsies in $21 \%(62 / 289)$ of cases versus $1 \%(2 / 214)$ and $15 \%$ (33/214) after CNB, respectively. ${ }^{44}$ Therefore, although cheaper as a single sampling procedure, FNAC requires additional histological tissue sampling (CNB and surgical excision biopsy) in a significant number of cases due to its lower accuracy. This stresses the important point that for final accurate diagnosis, routinely performing FNAC as an initial diagnostic procedure may be even more expensive than $\mathrm{CNB}$, although these results need to be confirmed in larger cohorts.

A high quality of patient care stands with a correct diagnosis as well as the efficacy to come to an optimal plan of treatment. So, the actual speed to come to a definite diagnosis matters. For FNAC, a routine May-Grunwald-Giemsa staining takes up to $1 \mathrm{~h}$, whereas a so-called Quick-diff enables a diagnosis in only 5 min, which provides a same-day diagnosis. The standard processing time to get to a histological diagnosis is usually approximately $24 \mathrm{~h}$. However, ultrafast tissue processing 
procedures now allow an accurate histological diagnosis within $4 \mathrm{~h}$ after sampling. FNAC might thus eventually result in a (only slightly to moderately) faster diagnosis, which is mainly relevant for patient comfort in the case of a benign diagnosis and no need for direct further treatment. However, this speed advantage in diagnosis becomes more relavant in the case of a malignant diagnosis, which requires discussion in a multidisciplinary team involving at least a surgeon, radiologist, medical oncologist, radiation oncologist and pathologist. Although some large centres can provide a frequent multidisciplinary meeting, which allows same-day discussion and therapy planning in a one-stop outpatient clinic in the case of FNAC, this is not an attainable option for most centres. It is our experience that a window of $36 \mathrm{~h}$ after $\mathrm{CNB}$ is in most cases sufficient to come to a definite and reliable diagnosis prior to such multidisciplinary meeting. In this workup scheme, patients get not only the final diagnosis but also the treatment plan right after the multidisciplinary meeting when they return to the outpatient clinic. Therefore, in the case of a (potentially) malignant breast lesion, the overall speed advantage of FNAC over CNB is relative. Noteworthy is that modified core wash cytology has been shown to correlate well with histology, with a sensitivity and specificity of $97 \%$ and $100 \%$, respectively. Combining this technique or imprint cytology with $\mathrm{CNB}$ histology may improve the quick and reliable diagnosis of malignant breast lesions. ${ }^{88}$

\section{CONCLUSIONS}

The diagnosis of breast cancer is usually accomplished by triple assessment (surgeon, radiologist and pathologist) in a multidisciplinary setting. FNAC and $\mathrm{CNB}$ are the most commonly used diagnostic modalities in the morphological diagnosis of breast tumours. In experienced hands, the sensitivity of FNAC is high, and not much lower than $\mathrm{CNB}$. The specificity of $\mathrm{CNB}$ is,

Table 1 Summary of benefits and limitations of FNAC and CNB

\begin{tabular}{lll}
\hline & FNAC & CNB \\
\hline Procedural (dis)advantages & & \\
Accessibility of deep sites & Yes & No \\
Level of experience required & High & Average \\
Success rate & $60-75 \%$ & $99 \%$ \\
Complication rate & Very low & Low \\
Diagnostic performance dependent on clinical/radiological features & \\
Non-palpable tumours & Low & High \\
Palpable lesions & High & High \\
Size $<10$ mm or $>40$ mm & Low & High \\
Diagnostic performance dependent on histological features & \\
Distinction between in-situ and invasive cancer & No & Yes \\
Diagnosis of pre-invasive lesions (CCL, ADH) & Low & High \\
Diagnosis of papillary lesions & Low & Moderate \\
Distinction between fibroadenoma & Moderate & High \\
and phyllodes tumour & & \\
Assessment of prognostic and predictive biomarkers & & \\
Grading & Low & Moderate \\
ER/PR assessment & Low & High \\
HER2 assessment & Low & High \\
Proliferation assessment & Moderate & High \\
DNA/RNA isolation for molecular test & Low & High \\
Cost/speed effectiveness & & \\
Speed & High & Moderate \\
Costs* & Very low & Low \\
\hline
\end{tabular}

*Costs: fine-needle aspiration cytology (FNAC) is cheaper as a single procedure but is overall likely to be more expensive to obtain a definitive diagnosis because of lower accuracy rates often necessitating additional core needle biopsy (CNB) or surgical excision. $\mathrm{ADH}$, atypical ductal hyperplasia; $\mathrm{CCL}$, columnar cell lesion; ER, oestrogen receptor; PR, progesterone receptor.

\section{Key messages}

FNAC and CNB are commonly used diagnostic modalities for breat lesions.

- Both have their own advantages and limitations.

- In general and based on overall performance indices, CNB is to be preferred over FNAC for the diagnosis of breast lesions.

however, higher as well as the positive predictive value for suspicious and especially atypical lesions and fibroepithelial lesions. Also, the inadequacy rate of FNAC for non-palpable lesions, the incidence of which has increased as a result of widely used screening programmes, is higher than for CNB. So, the overall performance indices of CNB are superior to FNAC in the majority of breast lesions. Ancillary immunohistochemical and molecular tests are more reliably and more easily performed on CNB than on FNAC, which is relevant to determine additional prognostic and predictive markers. Moreover, because of the increase in (neo)adjuvant treatment options, immunohistochemical and molecular profiling of individual tumour samples is increasingly important, especially in this new era of personalised medicine. Regarding cost effectiveness, the total costs to obtain a definitive, reliable diagnosis seem to be even higher for FNAC because of its low accuracy rate, especially for non-palpable and small lesions. FNAC is fast and therefore might be preferred for some palpable, probably benign lesions. In the case of (potential) malignancy, the speed advantage of FNAC over CNB seems relatively irrelevant in view of the required multidisciplinary meeting to arrive at a therapy plan. Therefore, taking into account the benefits and limitations of both techniques (table 1), we argue that $\mathrm{CNB}$ is to be preferred over FNAC for the diagnosis of breast lesions.

Funding SMW is funded by the Netherlands Organization for Scientific Research (Rubicon grant 2011/07046/ALW) and the Dutch Cancer Society (clinical fellowship: 2011-4964).

\section{Competing interests None.}

Contributors SMW wrote the manuscript. CHMvD and PJvD contributed significantly to the content and the writing of the manuscript.

Provenance and peer review Not commissioned; externally peer reviewed.

\section{REFERENCES}

1. Kooistra B, Wauters C, Strobbe L, et al. Preoperative cytological and histological diagnosis of breast lesions: a critical review. Eur J Surg Oncol 2010;36:934-40.

2. Tse GM, Tan PH. Diagnosing breast lesions by fine needle aspiration cytology or core biopsy: which is better? Breast Cancer Res Treat 2010;123:1-8.

3. Ibrahim AE, Bateman AC, Theaker JM, et al. The role and histological classification of needle core biopsy in comparison with fine needle aspiration cytology in the preoperative assessment of impalpable breast lesions. J Clin Pathol 2001:54:121-5.

4. Leifland K, Lagerstedt U, Svane G. Comparison of stereotactic fine needle aspiration cytology and core needle biopsy in 522 non-palpable breast lesions. Acta Radiol 2003; 44:387-91.

5. Garg S, Mohan H, Bal A, et al. A comparative analysis of core needle biopsy and fine-needle aspiration cytology in the evaluation of palpable and mammographically detected suspicious breast lesions. Diagn Cytopathol 2007;35:681-9.

6. Ballo MS, Sneige N. Can core needle biopsy replace fine-needle aspiration cytology in the diagnosis of palpable breast carcinoma. A comparative study of 124 women. Cancer 1996;78:773-7.

7. Shannon J, Douglas-Jones AG, Dallimore NS. Conversion to core biopsy in preoperative diagnosis of breast lesions: is it justified by results? J Clin Patho 2001;54:762-5.

8. Westenend PJ, Sever AR, Beekman-De Volder HJ, et al. A comparison of aspiration cytology and core needle biopsy in the evaluation of breast lesions. Cancer 2001;:93:146-50

9. Hatada $\mathbf{T}$, Ishii $\mathrm{H}$, Ichii $\mathrm{S}$, et al. Diagnostic value of ultrasound-guided fine-needle aspiration biopsy, core-needle biopsy, and evaluation of combined use in the diagnosis of breast lesions. J Am Coll Surg 2000;190:299-303. 
10. Khanna AK, Singh MR, Khanna S, et al. Fine needle aspiration cytology, imprint cytology and tru-cut needle biopsy in breast lumps: a comparative evaluation. $J$ Indian Med Assoc 1991:89:192-5.

11. Cheung PS, Yan KW, Alagaratnam TT. The complementary role of fine needle aspiration cytology and Tru-cut needle biopsy in the management of breast masses. Aust NZ J Surg 1987:57:615-20.

12. Barra Ade A, Gobbi H, de la Rezende CA, et al. A comparison of aspiration cytology and core needle biopsy according to tumor size of suspicious breast lesions. Diagn Cytopathol 2008;36:26-31.

13. Parker SH, Burbank F, Jackman RJ, et al. Percutaneous large-core breast biopsy: a multi-institutional study. Radiology 1994;193:359-64.

14. Nguyen M, McCombs MM, Ghandehari S, et al. An update on core needle biopsy for radiologically detected breast lesions. Cancer 1996;78:2340-5.

15. Fajardo LL, Pisano ED, Caudry DJ, et al. Stereotactic and sonographic large-core biopsy of nonpalpable breast lesions: results of the Radiologic Diagnostic Oncology Group V study. Acad Radiol 2004;11:293-308.

16. Doyle AJ, Murray KA, Nelson EW, et al. Selective use of image-guided large-core needle biopsy of the breast: accuracy and cost-effectiveness. AJR Am J Roentgenol 1995;165:281-4.

17. Cote JF, Klijanieko J, Meunier M, et al. Stereotactic fine-needle aspiration cytology of nonpalpable breast lesions: Institut Curie's experience of 243 histologically correlated lesions. Cancer 1998;84:77-83.

18. Silverman JF, Lannin DR, O'Brien $\mathrm{K}$, et al. The triage role of fine needle aspiration biopsy of palpable breast masses. Diagnostic accuracy and cost-effectiveness. Acta Cytol 1987;31:731-6.

19. Sneige N, Fornage BD, Saleh G. Ultrasound-guided fine-needle aspiration of nonpalpable breast lesions. Cytologic and histologic findings. Am J Clin Pathol 1994;102:98-101.

20. Giard RW, Hermans J. The value of aspiration cytologic examination of the breast. A statistical review of the medical literature. Cancer 1992;69:2104-10.

21. Boerner S, Fornage BD, Singletary E, et al. Ultrasound-guided fine-needle aspiration (FNA) of nonpalpable breast lesions: a review of 1885 FNA cases using the National Cancer Institute-supported recommendations on the uniform approach to breast FNA. Cancer 1999;87:19-24.

22. Liew PL, Liu TJ, Hsieh MC, et al. Rapid staining and immediate interpretation of fineneedle aspiration cytology for palpable breast lesions: diagnostic accuracy, mammographic, ultrasonographic and histopathologic correlations. Acta Cytol 2011:55:30-7.

23. Gordon PB, Goldenberg SL, Chan NH. Solid breast lesions: diagnosis with US-guided fine-needle aspiration biopsy. Radiology 1993;189:573-80.

24. Berner A, Davidson B, Sigstad E, et al. Fine-needle aspiration cytology vs. core biopsy in the diagnosis of breast lesions. Diagn Cytopathol 2003;29:344-8.

25. Clarke D, Sudhakaran N, Gateley CA. Replace fine needle aspiration cytology with automated core biopsy in the triple assessment of breast cancer. Ann $R$ Coll Surg Engl 2001;83:110-12.

26. Lieske B, Ravichandran D, Wright D. Role of fine-needle aspiration cytology and core biopsy in the preoperative diagnosis of screen-detected breast carcinoma. $\mathrm{Br} \mathrm{J}$ Cancer 2006:95:62-6.

27. Poole GH, Willsher PC, Pinder SE, et al. Diagnosis of breast cancer with core-biopsy and fine needle aspiration cytology. Aust NZ J Surg 1996;66:592-4.

28. Dennison G, Anand R, Makar SH, et al. A prospective study of the use of fine-needle aspiration cytology and core biopsy in the diagnosis of breast cancer. Breast $J$ 2003;9:491-3

29. Jackman RJ, Nowels KW, Shepard MJ, et al. Stereotaxic large-core needle biopsy of 450 nonpalpable breast lesions with surgical correlation in lesions with cancer or atypical hyperplasia. Radiology 1994;193:91-5.

30. Dahlstrom JE, Sutton S, Jain S. Histological precision of stereotactic core biopsy in diagnosis of malignant and premalignant breast lesions. Histopathology 1996;28:537-41.

31. Litherland JC, Evans AJ, Wilson AR, et al. The impact of core-biopsy on preoperative diagnosis rate of screen detected breast cancers. Clin Radiol 1996;51:562-5.

32. Rotten D, Levaillant JM, Leridon $\mathrm{H}$, et al. Ultrasonographically guided fine needle aspiration cytology and core-needle biopsy in the diagnosis of breast tumors. Eur $\mathrm{J}$ Obstet Gynecol Reprod Biol 1993;49:175-86.

33. Collins LC, Connolly JL, Page DL, et al. Diagnostic agreement in the evaluation of image-guided breast core needle biopsies: results from a randomized clinical trial. $A m$ J Surg Pathol 2004;28:126-31.

34. Gornstein B, Jacobs T, Bedard Y, et al. Interobserver agreement of a probabilistic approach to reporting breast fine-needle aspirations on ThinPrep. Diagn Cytopathol 2004;30:389-95.

35. Sriwatanakul K, Kelvie W, Lasagna L, et al. Studies with different types of visual analog scales for measurement of pain. Clin Pharmacol Ther 1983:34:234-9.

36. Daltrey IR, Kissin MW. Randomized clinical trial of the effect of needle gauge and local anaesthetic on the pain of breast fine-needle aspiration cytology. Br J Surg 2000;87:777-9.

37. Zagouri F, Sergentanis TN, Gounaris A, et al. Pain in different methods of breast biopsy: emphasis on vacuum-assisted breast biopsy. Breast 2008;17:71-5.

38. Satchithananda K, Fernando RA, Ralleigh G, et al. An audit of pain/discomfort experienced during image-guided breast biopsy procedures. Breast $J$ 2005:11:398-402.

39. Bates T, Davidson T, Mansel RE. Litigation for pneumothorax as a complication of fine-needle aspiration of the breast. Br J Surg 2002;89:134-7.
40. Meyer JE, Smith DN, Lester SC, et al. Large-core needle biopsy of nonpalpable breast lesions. JAMA 1999;281:1638-41.

41. Helvie MA, Ikeda DM, Adler DD. Localization and needle aspiration of breast lesions: complications in 370 cases. AJR Am J Roentgenol 1991:157:711-14.

42. He 0, Fan X, Yuan T, et al. Eleven years of experience reveals that fine-needle aspiration cytology is still a useful method for preoperative diagnosis of breast carcinoma. Breast 2007;16:303-6.

43. Bruening W, Fontanarosa J, Tipton K, et al. Systematic review: comparative effectiveness of core-needle and open surgical biopsy to diagnose breast lesions. Ann Intern Med 2010;152:238-46.

44. Hukkinen K, Kivisaari L, Heikkila PS, et al. Unsuccessful preoperative biopsies, fine needle aspiration cytology or core needle biopsy, lead to increased costs in the diagnostic workup in breast cancer. Acta Oncol 2008;47:1037-45.

45. Pisano ED, Fajardo LL, Tsimikas J, et al. Rate of insufficient samples for fine-needle aspiration for nonpalpable breast lesions in a multicenter clinical trial: the Radiologic Diagnostic Oncology Group 5 Study. The RDOG5 investigators. Cancer 1998;82:679-88

46. Barra AA, Gobbi H, de L Rezende CA, et al. A comparision of aspiration cytology and core needle biopsy according to tumor size of suspicious breast lesions. Diagn Cytopathol 2008:36:26-31.

47. Houssami N, Ciatto S, Ambrogetti D, et al. Florence-Sydney Breast Biopsy Study: sensitivity of ultrasound-guided versus freehand fine needle biopsy of palpable breast cancer. Breast Cancer Res Treat 2005:89:55-9.

48. Barrows GH, Anderson TJ, Lamb JL, et al. Fine-needle aspiration of breast cancer Relationship of clinical factors to cytology results in 689 primary malignancies. Cancer 1986:58:1493-8.

49. Manfrin E, Falsirollo F, Remo A, et al. Cancer size, histotype, and cellular grade may limit the success of fine-needle aspiration cytology for screen-detected breast carcinoma. Cancer Cytopathol 2009;117:491-9.

50. Sauer T, Garred 0, Lomo J, et al. Assessing invasion criteria in fine needle aspirates from breast carcinoma diagnosed as DICS or invasive carcinoma: can we identify an invasive component in addition to DCIS? Acta Cytol 2006;50:263-70.

51. Rahka EA, El-Sayed ME, Reed J, et al. Screen-detected breast lesions with malignan needle core biopsy diagnoses and no malignancy identified in subsequent surgical excision specimens (potential false-positive diagnosis). Eur J Cancer 2009;45:1162-7.

52. Provenzano E, Pinder SE. Pre-operative diagnosis of breast cancer in screening: problems and pitfalls. Pathology 2009;41:3-17.

53. Tan SM, Behranwala KA, Trott PA, et al. A retrospective study comparing the individual modalities of triple assessment in the pre-operative diagnosis of invasive lobular breast carcinoma. Eur J Surg Oncol 2002;28:203-8.

54. Boetes C, Veltman J, van Die L, et al. The role of MRI in invasive lobular carcinoma. Breast Cancer Res Treat 2004;86:31-7.

55. Weinstein SP, Orel SG, Heller R, et al. MR imaging of the breast in patients with invasive lobular carcinoma. AJR Am J Roentgenol 2001:176:399-406.

56. Dillon MF, McDermott EW, Hill AD, et al. Predictive value of breast lesions of "uncertain malignant potential" and "suspicious for malignancy" determined by needle core biopsy. Ann Surg Oncol 2007:14:704-11.

57. Houssami N, Ciatto $\mathrm{S}$, Ellis I, et al. Underestimation of malignancy of breast coreneedle biopsy: concepts and precise overall and category-specific estimates. Cancer 2007; 109:487-95

58. Sie A, Bryan DC, Gaines V, et al. Multicenter evaluation of the breast lesion excision system, a percutaneous, vacuum-assisted, intact-specimen breast biopsy device. Cancer 2006;107:945-9.

59. Killebrew LK, Oneson RH. Comparison of the diagnostic accuracy of a vacuumassisted percutaneous intact specimen sampling device to a vacuum-assisted core needle sampling device for breast biopsy: initial experience. Breast $J$ 2006:12:302-8.

60. Tse GM, Ma TK, Lui PC, et al. Fine needle aspiration cytology of papillary lesions of the breast: how accurate is the diagnosis? J Clin Pathol 2008;61:945-9.

61. Michael CW, Buschmann B. Can true papillary neoplasms of breast and their mimickers be accurately classified by cytology? Cancer 2002;96:92-100.

62. Jayaram G, Elsayed EM, Yaccob RB. Papillary breast lesions diagnosed on cytology. Profile of 65 cases. Acta Cytol 2007:51:3-8.

63. Field A, Mak A. A prospective study of the diagnostic accuracy of cytological criteria in the FNAB diagnosis of breast papillomas. Diagn Cytopathol 2007;35:465-75

64. Tse GM, Tan PH, Moriya T. The role of immunohistochemistry in the differentia diagnosis of papillary lesions of the breast. J Clin Pathol 2009;62:407-13.

65. Tan PH, Aw MY, Yip G, et al. Cytokeratins in papillary lesions of the breast: is there a role in distinguishing intraductal papilloma from papillary ductal carcinoma in situ? Am J Surg Pathol 2005;29:625-32

66. Kuijper A, Mommers EC, van der WE, et al. Histopathology of fibroadenoma of the breast. Am J Clin Pathol 2001;115:736-42.

67. Putti TC, Pinder SE, Elston CW, et al. Breast pathology practice: most common problems in a consultation service. Histopathology 2005:47:445-57.

68. Van Diest PJ, Kuijper A, Schulz-Wendtland R, et al. Fibroepithelial Tumors. Preneoplasia of the Breast. A New Conceptual Approach to Proliferative Breast Disease. Munich, Germany: Saunders/Elsevier, 2006:280-315.

69. Jara-Lazaro AR, Akhilesh M, Thike AA, et al. Predictors of phyllodes tumours on core biopsy specimens of fibroepithelial neoplasms. Histopathology 2010;57:220-32.

70. Shabb NS. Phyllodes tumor. fine needle aspiration cytology of eight cases. Acta Cytol 1997; $\mathbf{4 1 : 3 2 1 - 6}$ 
71. Bhattarai S, Kapila K, Verma K. Phyllodes tumor of the breast. A cytohistologic study of 80 cases. Acta Cytol 2000;44:790-6.

72. Robinson IA, McKee G, Nicholson A, et al. Prognostic value of cytological grading of fine-needle aspirates from breast carcinomas. Lancet 1994:343:947-9.

73. van Diest PJ, Risse EK, Schipper NW, et al. Comparison of light microscopic grading and morphometric features in cytological breast cancer specimens. Pathol Res Pract 1989;185:612-16.

74. van Diest PJ, Mouriquand J, Schipper NW, et al. Prognostic value of nucleolar morphometric variables in cytological breast cancer specimens. J Clin Pathol 1990; 43:157-9

75. Kwok TC, Rakha EA, Lee AH, et al. Histological grading of breast cancer on needle core biopsy: the role of immunohistochemical assessment of proliferation. Histopathology 2010;57:212-19.

76. Cahill RA, Walsh D, Landers RJ, et al. Preoperative profiling of symptomatic breast cancer by diagnostic core biopsy. Ann Surg Oncol 2006:13:45-51.

77. Usami S, Moriya T, Amari M, et al. Reliability of prognostic factors in breast carcinoma determined by core needle biopsy. Jpn J Clin Oncol 2007;37:250-5.

78. Burge CN, Chang HR, Apple SK. Do the histologic features and results of breast cancer biomarker studies differ between core biopsy and surgical excision specimens? Breast 2006;15:167-72

79. Andrade VP, Gobbi H. Accuracy of typing and grading invasive mammary carcinomas on core needle biopsy compared with the excisional specimen. Virchows Arch 2004:445:597-602
80. Di LC, Puglisi F, Rimondi G, et al. Large core biopsy for diagnostic and prognostic evaluation of invasive breast carcinomas. Eur J Cancer 1996;32A:1693-700.

81. Harris GC, Denley HE, Pinder SE, et al. Correlation of histologic prognostic factors in core biopsies and therapeutic excisions of invasive breast carcinoma. Am J Surg Pathol 2003;27:11-15.

82. Badoual C, Maruani A, Ghorra C, et al. Pathological prognostic factors of invasive breast carcinoma in ultrasound-guided large core biopsies - correlation with subsequent surgical excisions. Breast 2005;14:22-7.

83. Sharifi S, Peterson MK, Baum JK, et al. Assessment of pathologic prognostic factors in breast core needle biopsies. Mod Pathol 1999;12:941-5.

84. Rakha EA, Ellis IO. An overview of assessment of prognostic and predictive factors in breast cancer needle core biopsy specimens. J Clin Pathol 2007;60 $1300-6$.

85. Konofaos P, Kontzoglou K, Georgoulakis J, et al. The role of ThinPrep cytology in the evaluation of estrogen and progesterone receptor content of breast tumors. Surg Oncol 2006;15:257-66

86. van Diest $\mathbf{P J}$, van der WE, Baak JP. Prognostic value of proliferation in invasive breast cancer: a review. J Clin Pathol 2004;57:675-81.

87. Lannin DR, Silverman JF, Walker C, et al. Cost-effectiveness of fine needle biopsy of the breast. Ann Surg 1986:203:474-80.

88. Wauters CA, Sanders-Eras MC, de Kievit-van der Heijden IM, et al. Modified core wash cytology (CWC), an asset in the diagnostic work-up of breast lesions. Eur $\mathrm{J}$ Surg Oncol 2010:36:957-62

Advancing Postgraduates. Enhancing Healthcare.

The Postgraduate Medical Journal is dedicated to advancing the understanding of postgraduate medical education and training.

- Acquire the necessary skills to deliver the highest possible standards of patient care

- Develop suitable training programmes for your trainees

- Maintain high standards after training ends

Published on behalf of the fellowship for Postgraduate Medicine

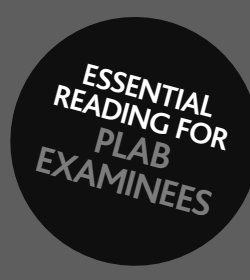

FOR MORE DETAILS OR TO SUBSCRIBE, VISIT THE WEBSITE TODAY

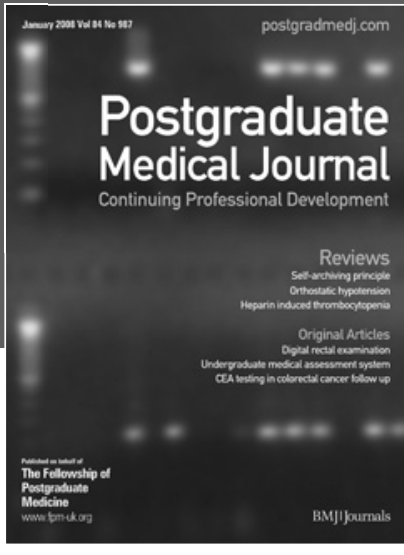

\section{postgradmedj.com}

